\title{
Aesthetic Quality in Theatre as a Genre of Performance
}

\author{
Lei Zhu ${ }^{1}$ \\ ${ }^{1}$ School of Foreign Languages, University of Jinan, China \\ Correspondence: Lei Zhu, School of Foreign Languages, University of Jinan, China. E-mail: \\ sfl_zhul@ujn.edu.cn
}

Received: July 6, 2012 Accepted: August 5, 2012 Online Published: August 30, 2012

doi:10.5539/ijel.v2n5p55 URL: http://dx.doi.org/10.5539/ijel.v2n5p55

\begin{abstract}
The specific qualities of theatre distinguish itself from any other literary genres. As a theatre presupposes performance, undoubtedly then, it must contain the factors that make it playable. The aesthetic constitution of a theatre and the characteristics of theatrical discourse, which, together with the aesthetic quality of theatre as a branch of literature, make the total charm of a piece of theatrical creation.
\end{abstract}

Keywords: aesthetic quality, theater, drama

\section{Introduction}

There is a remarkable difference between a play and any other forms of literature. A play is not really a piece of literature for reading. In the opening part of his book, Boulton points out "a true play is three-dimensional; it is literature that walks and talks before our eyes" (Boulton, 3). It is not intended that the eye shall perceive marks on paper and the imagination turn them into "sights, sounds and actions; the text of the play is meant to be translated into sights, sounds and actions, which occur literally and physically on a stage” (Boulton, 3). A theatre text is read differently. It is read as something incomplete, rather than as a fully rounded unit, since it is only physical. It would seem more logical, therefore, to proceed on the assumption that a theatre text, written with a view to its performance, contains distinguishable structural features that make it performable, beyond the stage directions themselves. Consequently, theatre in nature is a kind of performing art.

\section{Dramatic Dramatism and Theatrical Theatricality}

What is theatre? The word comes from the Greek theatron, or "seeing place". It is a place where something is seen. And the companion term drama comes from the Greek dran, "to do". It is something done. An action. Theatre: something is seen; something is witnessed.

Theatre is the art of making play into work-specifically, into a work of art. It is exhilarating work, to be sure, and it usually inspires and invigorates the energies and imaginations of all who participate. The theatre is artistic work. The word art brings to mind hosts of intangibles: creativity, imagination, elegance, power, aesthetic harmony, and fineness of form. Furthermore, we expect a work of art to capture something of the human spirit and to touch upon senses, but intellectually elusive, meanings in life. Certainly great theatre never fails to bring together many of these intangibles.

The art of the theatre is never pure art in the sense that it represents the personal vision of a solitary artist. Indeed, many pure artists consider theatrical art a bastard form, combining as it does the several arts of acting, writing, designing, directing, and architecture (Cohen, 15).

A play is a piece of life-animated, shaped, and framed to become a work of art. It provides a structured synthesis—-sometimes a critique and sometimes a celebration—of both life's glories and life's confusions. Of course, a play is also a piece of literature. There has been a reading audience for plays at least since the time of the ancient Greeks, and play collections_such as Shakespeare's works-have been published since the Renaissance. Today plays are often printed in literary anthologies, intermixed with poems, short stories, and even novels. But drama should not be thought of as merely a branch, or genre of literature; it is a live performance, some of whose repeatable aspects may be captured in a written and published text.

Dramatic dramatism and theatrical theatricality (Dong Jian, 65-68) are all the key elements of a piece of play. They are different from each other. Dramatic dramatism is fully expressed in the poetic language employed in 
plays while theatrical theatricality in the performance of plays. Language is the medium of dramatism and spoken line of theatricality. Dramatic dramatism is created by the playwright and director while theatrical theatricality by director and actors. Since theatricality has little relationship with the dramatic text as for the problem of translating, it will not be explored in this paper.

Dramatic dramatism is the inborn aesthetic quality of a piece of theatrical text. It is displayed in the following ways (Cohen, 84-94).

\subsection{Compression, Economy, and Intensity}

Compression, economy and intensity are a set of related aspects of the finest plays. Compression refers to the playwright's skill in condensing a story into a theatrical time frame; economy relates to one's skill in eliminating or consolidating characters, events, locales, and words in the service of compression. Unlike other literary or visual art forms that can be examined in private and at the leisure of the observer, a play must be structured to unfold in a public setting and at a predetermined pace. If the playwright can manage to meet these needs and at the same time to make every scene, every incident, every character, every word deliver an impact, he or she has satisfied the dramatic demand for intensity.

The effects of economy and compression are both financial and aesthetic. Obviously, when scenery changes and the number of characters are held to a minimum, the costs of production are minimized as well. But beyond that and more important, compression and economy in playwriting serve to stimulate intrigue and focus audience expectation: a tightly written play gives us the feeling that we are on the trail of something important and that our quarry is right around the next bend. In other words, economy and compression actually lead to intensity, and dramatic intensity is one of the theatre's most powerful attributes.

Dramatic intensity can take many forms. It can be harsh, abrasive, explosive, eminently physical, or overtly calm. It can be ruminative, tender, or comic. But whenever intensity occurs and in whatever mood or content, it conveys to the audience an ineradicable feeling that this moment in theatre is unique and its revelations are profound. Intensity does not come about by happy accident, obviously, but neither can it be straightforwardly injected at the whim of the playwright. It must evolve out of a careful development of issues, through the increasing urgency of character goals and intentions and the focused actions and interactions of the plot that draw characters and their conflicts ever closer to some sort of climactic confrontation. A play must spiral inward toward its core; that is, its compression must increase, its mood must intensify, as it circles toward its denouement. Too many tangential diversions can deflect a play from this course and render it formless and apparently devoid of purpose.

\subsection{Intrigue}

Intrigue is the quality of a play that makes us curious (sometimes fervently so) to see "what happens next". Sheer plot intrigue - which is sometimes called "suspense" in that it leaves us suspended—is one of the most powerful dramatic approaches. Whole plays can be based on little more than artfully contrived plotting designed to keep the audience in a continual state of anticipation and wonder. Plot, however, is only one of the elements of a play that can support intrigue. Most plays that aspire to deeper insights than whodunits or farces develop intrigue in character as well and even in theme. Most of the great plays, in fact, demand that we ask not so much "what will happen?” as "what does this mean?” Most great plays, in other words, make us care about the characters and invite us to probe the mysteries of the human condition.

Surprise is an essential ingredient of intrigue: a play that is truly intriguing is one that leads us to expect surprises and then appropriately rewards our expectations. The plays of Harold Pinter, which are filled with abrupt, almost inexplicable transitions, intense pauses and glances, and elliptical dialogue that seems to contain innuendos we don't fully comprehend, create an almost palpable sense of foreboding and spookiness that plunges the audience deeper and deeper into Pinteresque moods and reveries.

Intrigue draws us into the world of a play; credibility keeps us there. In the best plays the two are sustained throughout the course of the action in a fine tension of opposites: intrigue-demanding surprise, credibility demanding consistency. Combined, they generate a kind of "believable wonder", which is the fundamental state of drama. All the credibility in the world will not suffice by itself to make a play interesting, and all the intrigue that craft can contrive will fail to make incredible play palatable. The integration of the two must be explored by the playwright in order to establish that shared ground that satisfies both human inertia and human potential, that transcends our expectations but not our credulity.

\section{Theatrical Discourse}

We can say that a play consists basically of dialogue and stage directions. Dramatic dialogue is all that a drama 
bases itself on. The plot is to be developed through dialogue lines; the characterization also has to be realized through the dialogues between characters themselves; and even the playwright's opinion on each character is told by the words from their own mouths, for, unlike an omnipresent novelist who can probe into the mind of any character to give a vivid description or jump out as an observer to make objective comments, a playwright has no place for his own voice in the play; the voice is melted in or embodied by various characters. In a word, the dialogue is the sole means of a playwright.

Once we accept that the written text is not fundamental to performance but is merely one element in an eventual performance, and then this means that the translator, like the writer, although need not be concerned with how that written text is going to integrate into the other sign systems on the stage, it is their responsibility to take the whole performing effects into consideration. That is to say, theatre is a collaborative process in which not only are different sign systems involved, but a host of different people with different skills. As one element of the eventual performance of theatre, the dramatic text should be in harmony with other sign systems involved. We need to look at the dramatic text as both literature and performing art, and this seems a helpful starting point for the translator. The written text is a functional component in the total process that comprised theatre and is characterized in ways that distinguish it from a written text designed to be read in its own right. In theatre text there are certain distinctive features of the written text, for example, how dialogue unfolds both in time and in space and is always integrated in the extra linguistic situation, which comprised both the things that surround the speakers and the speakers themselves.

The language employed in the writing of a play is quite different from the language used in other form of literary writing. Because theatre is an art of performance, its blue prints, that is, the dramatic text, should contain the characteristics of being a performing art.

\subsection{Speakability and Stageability}

"The plays of great dramatists — and it is possible to be a very great writer without being a great dramatist-are always better acted than read.”(Boulton, 27) The dialogue of drama is written on the page, but it must be spoken by an actor and staged by a director. We should not forget that they are also there to give the great actor or actress an opportunity to show skill and fervor in the handling if emotion. Thus the goal of the dramatist is to fabricate dialogue that is actable and stageable and that flows in a progression leading to theatrical impact.

This is not to say that play dialogue must resemble ordinary speech exactly. Rather, speakability means that a line of dialogue should be so written that it achieves its maximum impact when spoken. In order to accomplish this, the rhythm of the sound that creates emphasis on meaning, focus, and power.

Stageability, of course, requires that dialogue be written so that it can be spoken effectively upon a stage, but it requires something more: dialogue must be conceived as an integral element of a particular staged situation, in which setting, physical action, and spoken dialogue are inextricably combined. Lyrical dramatic dialogue and physical stage behavior are shaped into a dramatic unity that cannot be expressed outside the theatrical context itself. A stageable script is one in which staging and stage business are neither adornments for the dialogue nor sugarcoating for the writer's opinions but are intrinsic to the very nature of a stage play.

Both speakability and stageability are contingent upon human limitations: those of the actors and directors as well as those of the audience. Speakability must take into account that the actor must breathe from time to time, for example, and that the audience can take in only so many metaphors in a single spoken sentence. A speakable and stageable script flows rather than stumbles; this is true for nonlinear plays as well as for more straightforwardly structured ones. Flow consists above all in the creation of a continual stream of information, and a play that flows is one that is continually saying something, doing something, and meaning something to the audience. That is to say, the dialogue of a play must be such that the normally competent actor can speak his lines without stumbling, stopping for breath in the wrong place or speaking with so little animation or such a false intonation that it is obvious he does not understand what he is saying; it must also be such that the audience for whom the pay is written can take in most of what is being said in the time available.

The charm of theatre mainly comes from actions. The reason why theatre is attractive is that on the stage the audience can see the conflict between the friends and enemies during which their ideas, emotions and passion influence each other and change their relationship in between; and therefore this kind of language can push forward the development of the plot as well as reveal the inner activity of the characters.

\subsection{Different Speech of Individual}

Another important aspect of dialogue is the differentiation of the speech of individuals. "It is an obvious fact that people who claim to be users of the same language do not speak the language in the same manner". (Dai 
Weidong, 137) For example all the Chinese speakers do not speak the same type of Chinese. Many people do not talk in sentences; people who are shy, uneducated or unintelligent do not often talk in sentences; and many of the human races come into one of these three categories. No one talks in sentences all the time: animal grunts, one-word answers to questions, unfinished sentences, slovenly grammar, ellipses, vulgarisms, vague remarks, polite formula, are all found in abundance even in the normal conversation of cultured people. A play, then, in which everyone spoke the exact language of contemporary ordinary speech would dray, irritate and be unbearably dull.

Generally speaking, every person has his own way of speaking that can reveal his identity, social status, education, and his quality as well. Speech is, in real life, a considerable clue to social positions, standards of education, character and habits. Emanating from a character, the spoken line is distinguished by syntax, vocabulary, and expression mode. And all these are the marks of that character's milieu and his or her personality. The spoken line is not merely an expression of the author's perspective; it is the basis from which the actor develops characterization and the acting ensemble creates a play's style.

"Linguistic expression in theatre is a structure of signs constituted not only as discourse signs, but also as other signs. For example, theatre discourse that must be the sign of a character's social situation is accompanied by the actor's gestures, finished off by his costumes, the scenery, etc. which are all equally signs of a social situation.”

(Bassnett, 121)

In addition, different people handle their words with different cadence rhythm and different tone and intonation.

\subsection{Rich Implications}

Being implicit is the tradition of Chinese poetry and opera, because the artistic and poetic language presupposes indirect expression. In this way the meaning conveyed is beyond the semantic meaning of the words; the expressiveness of the language is reinforced. Rich implications in the language are one of the most important characteristics of being a theatrical text. It is the most powerful way to create images. The sentences in plays usually are plain and simple, and at the same time, these short sentences convey profound meanings as well. For the audience, this kind of language provides enough material for their chewing and digestion; for the actors, it offers them adequate implications for their creation in the performance.

Implications in dramatic text lie between the spoken lines, which are not expressed directly by the playwright but can fully reveal the speaker's read ideas. Sometimes, in order to achieve a certain aim, a character may use direct expressions; at that time the implied meaning is in accordance with the linguistic meaning of the expressions. But more often, the character cannot talk directly under subtle relationship among the people present. They speak out their ideas in a roundabout way, which is full of overtones; at that time the implied meaning of the expressions is beyond the linguistic meaning conveyed by the expressions.

\subsection{Credibility}

Credibility is the basic quality of a play. To say that a play must be credible is not at all to say that it has to be lifelike, for fantasy, ritual, and absurdity have all proven to be enduringly popular theatrical modes. The demand of credibility is an audience-imposed demand, and it has to do with the play's internal consistency: the actions must flow logically from the characters, the situation, and the theatrical context the playwright provides. Credibility demands, for example, that the characters in a play appear to act out of their own individual interests, instincts, and intentions rather than serving as mere pawns for the development of theatrical plot or effect, as empty disseminators of propaganda. Credibility means that characters must maintain consistency within themselves: that their thoughts, feelings, hopes, fears, and plans must appear to flow from human needs rather than purely theatrical ones. Credibility also demands that human characters appear to act and think like human beings (even in humanly impossible situations) and not purely as thematic automatons.

One important way to keep a theatre credible is to employ the language used in daily practice. Since all the characters on the stage are considered as the human beings in real life rather than purely theatrical ones, they should speak like ordinary people. And at the same time a theatre is completed only in its performance; therefore, the massage sent during the performance should be accepted at the same time it is sent. In other words, the language should be easy for the audience to understand. Daily language is formed in common practice, and it helps to reinforce the credibility and the performing effect of a theatre.

But it does not follow that all the daily expressions can find their way into a theatrical text. Though drama is a heightened, not a photographic, representation of life-a purely realistic portrayal would give no pleasure-it must give the illusion of reality when we are watching it. Written for actors and actresses to say and perform on a 
stage, a dramatic text, however, is far from being a short-hand or a raw recording of the ordinary language in our life; it undoubtedly belongs to the artistically processed and refined language just as that of novel and poetry. Since some daily words are crude and need refining, some of them even are dialects or obsolete words; they should be refined to meet the need of a theatre. Theatrical discourse should be poetic. All the daily expressions used in theatre are recreated by literary method. Therefore the language used in play should be easy to understand and have poetic flavor as well. It resembles the language in daily life and has the quality of a poem at the same time. This is the true dramatic language that has emotion and profound musical charm in itself.

\section{Conclusion}

Theatre is a special member of the literature family in that it doubles as a branch of the performing art. It follows that the aesthetic constitutions of a dramatic creation is a complex problem, which needs to be settled before the reproduction of these artistic features in translation. The chief aesthetic qualities of a drama lie in its performability which can be displayed in several ways as compression, economy, intensity and intrigue. On the other hand, as a subgenre of literature, a theatrical text also shares the aesthetic value with other literary creations, which mainly lie latently in the languages.

\section{References}

Bassnett, Susan, \& Lefevere, André. (2001). Constructing Cultures. Shanghai: Shanghai Foreign Language Education Press.

Bassnett, Susan. (2004). Translation Studies (3rd ed.). Shanghai: Shanghai Foreign Language Education Press.

Boulton, Marjorie. (1960). The Anatomy of Drama. London, Henley \& Boston: Routledge \& Kegan Paul.

Cohen, Robert. (2000). Theatre Brief Version (5th ed.). New York: McGraw-Hill Book Company.

Dong, Jian. (2004). Fifteen Lectures on Drama. Beijing: Peking University Press.

Hatim, Basil, \& Mason, Ian. (2002). Discourse and the Translator. Shanghai: Shanghai Foreign Language Education Press.

Herman, Vimala. (1995). Dramatic Discourse: Dialogue as Interaction in Plays. Great Brain: T. J. Press (Padstow) Ltd.

Liu, Zhongde. (2000). Ten Lectures on Literary Translation. Beijing: China Translation and Publishing Corporation.

Mauron, Charles. (1927). The Nature of Beauty in Art and Literature. Tavistock Square: Leonard \& Virginia Woolf at The Hogarth Press. 